\title{
Facilitating Flow Experience in People with Intellectual Disability Using a Music Intervention Program
}

\author{
Amanallah Soltani \\ Faculty of Educational Studies, University Putra Malaysia \\ Serdang, Selangor, 43400, Malaysia \\ E-mail: Soltanimani@yahoo.com \\ Samsilah Roslan (Corresponding author) \\ Faculty of Educational Studies, University Putra Malaysia \\ Serdang, Selangor, 43400, Malaysia \\ Tel: 60-389-468-194Ｅmail: samsilah@educ.upm.edu.my
}

Maria Chong Abdullah

Faculty of Educational Studies, University Putra Malaysia

Serdang, Selangor, 43400, Malaysia

Tel: 60-389-468-212Ｅmail: maria@educ.upm.edu.my

\author{
Chan Cheong Jan \\ Faculty of Human Ecology, University Putra Malaysia \\ Serdang, Selangor, 43400, Malaysia
}

Tel: 60-389-467-120 Email: chan@putra.upm.edu.my

Received: July 18, $2011 \quad$ Accepted: August 9, $2011 \quad$ Published: December 1, 2011

doi:10.5539/ijps.v3n2p54 URL: http://dx.doi.org/10.5539/ijps.v3n2p54

\begin{abstract}
Flow is an internal state defined as a condition whereby a person is intensively involved in an activity and ignores the time spent and the place that he/she is in. The purpose of this paper is to empirically support strategies that are assumed to facilitate flow experiences among people with intellectual disability using a music intervention program. For this purpose, thirty adolescents and young adults with mild to moderate intellectual disability were randomly selected to participate in a within subject experimental design with four conditions. The results of one way repeated measure ANOVA and its following comparisons in pairs revealed that the participants were unable to sustain flow experience when no optimal challenge was provided for them. However, providing successful optimally challenging musical experiences for these people or stimulating them to look for new challenges by involving them in innovative behaviors are effective strategies to facilitate their flow experiences.
\end{abstract}

Keywords: Intellectual disability, Flow experience, Optimal challenge, Music intervention program

\section{Introduction}

Csikszentmihalyi $(1975,1990,1996)$ analyzed the findings gathered from interviews, questionnaire and self reports of people engaged in diverse activities such as musical activities, chess playing, rock climbing, composing and surgery. He found that regardless of the different activities they are involved in at the time, the people experience the same feelings when doing what they really enjoy. He termed this as "flow" and described it as a feeling of "being carried away by an outside force, of moving effortlessly with a current of energy, at the moments of highest enjoyment" (Csikszentmihalyi 2003, p, 39). Many successful scientists, artists, physicians, 
lawyers, and business leaders have reported experiencing this flow when they are deeply engaged in their activities. However, unfortunately there are many people with intellectual disability who are unable to experience this joyful feeling as their routine activities are devoid of adequate challenges.

Csikszentmihalyi $(1975,1990)$, in his theory of flow experience, developed six dimensions that constitute flow and three conditions that facilitate it. The six dimensions are involvement in an activity with a high level of concentration, feeling a sense of control during the activity, loss of self consciousness, merging of action and awareness, losing perception of time (altered time perception) during the activity, and a feeling of autonomy. The three facilitators of flow experience are providing clear goals for the activity, giving immediate unambiguous feedback, and striking an appropriate balance between skill and challenge (optimal challenge).

The importance of optimal challenge or, in other words, the balance between skill and challenge to facilitate flow experience was emphasized in Csikszentmihalyi's theory of flow experience. It was mentioned that, during any activity, people experience flow, only when their perception of skill and challenge are high and equal. In other words, when the highest skills meet the highest challenges, flow experience will be optimized (Csikszentmihalyi 1975, 1990). Some researchers tried to support the importance of optimal challenge to facilitate flow experience, as mentioned by the theory of flow experience, in non disabled people. For instance, Rheinberg \&Vollmeyer (2003) conducted an experimental study where the difficulty level of computer games was manipulated to determine its effect on experiencing flow while the two other facilitators of flow experience (clear goals and unambiguous feedback) were held constant. The three levels of tasks difficulty in this study were low, moderate, and high. The participants showed significantly higher levels of flow experience when the levels of task difficulty were moderate compared to when the levels of task difficulty were easy or difficult.

Sackett (2008) subsequently expanded the previous study and examined the interactive effect of skill-challenge balance and goals on experiencing flow while feedback was held constant. The findings of this study showed that participants demonstrated a higher level of flow experience when they perceived moderate challenge. However, different types of goals (instructional-only goals, experiential goals, and performance goals) do not appear to inhibit flow experience.

The studies conducted by Rheinberg \& Vollmeyer (2003), and Sackett (2008) provided partial support for the importance of skill-challenge balance for experiencing flow. However, in these studies, the challenge or task difficulty was the only variable which was manipulated while skill was assumed to be the same across all participants. It is not a direct study of skill-challenge balance because to examine the balance between skills and challenge, both variables should be taken into account. Thus, later Keller \& Bless (2008) took a more direct approach to analyze the effect of manipulating optimal challenge on flow experience. An experimental design was used to test for the causal impact of the skill-challenge balance on flow. The task was a computer game that had different distinct playing modes. The expanded condition was designed to keep challenge at a very low level so that participants were over-skilled for the game. The adaptive condition was designed to create a balance between skill and challenge by automatically adapting the level of difficulty of the game to the individual participant's skill level, thereby making it very challenging for their skill level. The researchers found that the participants in the adaptive condition were more likely to experience flow. The approach of Keller \& Bless(2008) in manipulating optimal challenge is superior to previous studies as the participant's individual skill-level was taken into account, rather than assuming that all the participants had approximately the same skill level.

The studies mentioned above proved the positive effect of optimal challenge in facilitating flow experience, as proposed by the theory of flow experience, during computer game playing among people without any disability. However, no studies were found that confirm its effect on people with intellectual disability, using some special intervention program.

People with intellectual disability (ID) usually suffer from a variety of physical, cognitive, and learning problems which negatively affect their functional ability (Taylor, Richards, \& Brady, 2005). The low functional abilities of people with ID, resulting from their cognitive or physical problems, are usually reflected in their failures, especially when they are involved in some physical, social, or cognitive mastery situations. Experiencing repeated failures in such situations may result in them feeling anxious in new mastery situations (Harter, 1978; Zigler \& Bennett-Gates, 1999). A strategy that the intellectually disabled may use to avoid the feeling of anxiety is to escape from mastery situations by being involved in situations that have no challenging outcome (Zigler, and Bennett-Gates, 1999). Such situations exist in some vocational training centers and sheltered workshops, where the intellectually disabled participate in routine activities such as sealing envelops, packing, sorting and folding pamphlets. These activities are usually repeated daily and throughout the whole day. Although being involved in such continuous routine activity might prevent people with ID from feeling anxiety, due to lack of 
optimal challenge, it might however undermine their flow experience.

Thus, considering the importance of optimal challenge to facilitate flow experience, it could be assumed that, apart from giving immediate feedback and clear goals, providing optimally challenging successful experiences for people with ID, or stimulating them to look for optimal challenge, by involving them in successful innovative behaviors may facilitate their flow experience. This study was aimed at confirming this assumption, using a music intervention program.

\section{Method}

\subsection{Participants}

Thirty participants were randomly selected from a population of 120 adolescents and young adults with mild to moderate intellectual disability, in two vocational training centers and one sheltered workshop of Wisma Harapan organization in Malaysia. The participants were 20 males and 10 females, aged between 15-25 years. All the participants grew up with their family and communities, attended special primary schools, and had no behavioral problems, paralysis, and deafness. They were always involved in routine activities such as sealing envelops, packing, sorting, and folding pamphlets throughout the day from 8 am to $4 \mathrm{pm}$, under the supervision of three teachers.

The parents or guardians of the participants signed the informed consent form and agreed for the research project to be conducted. In addition, a written consent was obtained from the manager of the organization.

\subsection{Research Design}

In this study, a one-group within-subject experimental design or, in other words, a one-group repeated-measure experimental design was used. It is difficult for most researchers dealing with special population, to find a large sample of participants to form different groups and handle the group teaching process during an experiment. A within-subject experimental design, which requires the formation of only one group, is considered as an applicable alternative (West, Biesanz, \& Kowok, 2004). Given the high level of individual differences among people with intellectual disability (Foreman, 2009), using a within-subject experimental design removes the variance caused by individual differences (Gravetter \& Forsano, 2008). Thus, in the current study, a one group repeated-measure experimental design was used to manage the sample, handle individual teaching process, and remove variance caused by individual differences. An individualized music intervention program with four conditions was applied to conduct the repeated-measure experimental design for the present study.

\subsection{Music Intervention Program}

An individualized music intervention program with four conditions was conducted for a period of four months. In the following sections, the musical tasks, special teaching strategies, and special musical instruments used in the program are mentioned. This is followed by an explanation of the place, time schedule, and four conditions of the program and the process of selecting appropriate musical tasks under each condition.

\subsubsection{Musical Tasks Used in the Music Intervention Program}

Given the individual differences in the potential ability of the intellectually disabled (Foreman, 2009), a continuum of melodies with varying challenge levels, from very simple to more complex ones, was used to provide appropriate musical tasks during the program. These tasks were selected during a trial run based on their appropriateness with Malaysian culture. An eight month trial run was carried out before the main research was conducted. In the trial run, 5 people with mild to moderate intellectual disability, aged between 6 to 20 years, who were not participants of the main study, were taught weekly to perform some musical tasks, which were popular in Malaysian culture. At the end of the trial run, all the 5 people were able to play the musical tasks given, based on their ability levels. This trial run provided the best opportunity for the researchers of this study to become familiar with the musical culture of Malaysia and assisted them in finding the best simple musical melodies, most common among the majority of Malaysians.

\subsubsection{Special Teaching Strategies Used in the Music Intervention Program}

Taking cognizance of the restricted abilities and limitations of people with intellectual disability, the special teaching strategies used in the music intervention program were (a) musical task analysis, in which the tasks to be taught were broken down into smaller and sequential units, (b) stating the lesson's goals clearly and providing appropriate feedbacks, (c) repeating materials, skills and concepts several times, (d) speaking in short simple sentences without talking down, (d) performing one musical task rather than multiple tasks, (e) adapting the amount of time allocated to complete a task, and (f) using auditory rote learning or, in other words, teaching music by ear instead of notation. 


\subsubsection{Musical Instruments Used in the Music Intervention Program}

Given the limitations of the intellectually disabled in their sensory-motor coordination (Taylor, et al., 2005), it was necessary to provide a standard and attractive musical instrument, having simple physical nature and beautiful sounds. A metal xylophone (soprano) which has these characteristics (Bitcon, 2000) was selected as the instrument to be used in the program. In addition, due to their cognitive, memory and attention problems (Taylor et al., 2005), the intellectually disabled might be unable to follow the beats correctly (beats are some regular pulsations or equal units of time in a rhythmic pattern). An auto accompaniment system was used to help the participants follow the beats. Auto accompaniment is a system, a sort of sound mirror, which is able to produce music in the same style as a person playing his or her own instrument.

\subsubsection{Place, Time Schedule, and the Four Conditions of the Music Intervention Program}

A small quiet room with appropriate facilities in Wisma Harapan organization center in Malaysia was selected as the experimental room. All the thirty participants were invited to the experimental room in person, to be involved in a half an hour individualized session, twice a week. So each participant had 40 individualized sessions conducted during the four conditions of the music program.

The first condition of the music intervention program conducted during the first ten sessions of the program was labeled as "providing successful experiences with optimal challenge for the first time". The musical tasks were taught to each participant individually by selecting the first simple melody in the continuum of musical tasks. When the participant mastered the first task, the second but more difficult task was taught. This process continued for the third, fourth, fifth and the other more difficult tasks depending on his/her ability. Due to their individual differences, the number of tasks mastered by the participants differed. For example, during this condition, one participant might be able to master only the first two tasks in the continuum of the musical tasks, but another participant with higher potential ability might be able to master the first six musical tasks. It was characterized as a situation with real challenge-skill balance, in which the level of challenge was individually balanced with the real ability level of each participant. At the end of this condition, 6 participants mastered the first three tasks, 11 participants mastered the first 4 tasks, 7 participants mastered the first 5 tasks, and 6 participants mastered the first 6 tasks.

The second condition of the experiment, introduced during the second ten sessions of the music intervention program was labeled as "providing no optimal challenge". Here the participants were not taught to master any new musical tasks. Instead, they were free to experiment with the tasks that they had already mastered during the first condition, or perform innovative tasks, or do nothing at all. It was a boring situation in which the experimenter did not provide any new tasks with higher level of difficulty to the participants. In other words, no optimal challenges were provided in this second condition.

The third condition of the experiment, conducted during the subsequent ten sessions of the program, was called "providing optimal challenge for the second time". Here each participant individually continued to master new musical tasks in the continuum where he/she had stopped in condition one. For example, if one participant had mastered the first three melodies during the first condition, then he/she was taught to master new progressive melodies higher than the third melody in the continuum. This was known as "providing optimal challenge for the second time" because for the second time each participant, based on his/her ability, was involved in some unlimited progressive musical tasks, which increasingly provided enough challenge, as his/her functional ability improved through practice.

The fourth condition of the experiment, conducted in the last ten sessions of the music intervention program was known as "stimulating to look for optimal challenge". As in condition two, here the experimenter did not provide any optimal challenge. In other words, he did not present any new melody from the continuum of musical tasks. However, he stimulated the participants to make new original tasks by using strategies such as modeling creative features and question and answer as a scaffolding strategy. With respect to modeling strategies, the experimenter, based on the ability of the participants, modeled some simple creative features of musical tasks and then encouraged the participant to do something similar but in his/her own way. To use question and answer as a scaffolding strategy, the experimenter performed a simple creative melody as a question and encouraged the participant to perform his/her own innovative melody as a response to the experimenter's question. The experimenter gradually encouraged the participant to use one of his/her hand as a questioner and the other as the respondent. This condition was called "stimulating optimal challenge" because the participants were stimulated to seek-out optimal challenge by creating new original musical tasks.

Apart from manipulating optimal challenge, informative feedback and clear goals, as the other two influential facilitators of flow experience, were provided during the music intervention program. 


\subsection{Measures}

As the intellectually disabled are unable to use literary skills and express their internal state appropriately, observational strategies, in which the participant's behaviors are observed during activities, could be the best strategy to assess their intrinsic motivation aspects. Thus, in this study, the observational indicators of flow experience introduced by Custodero $(1997,2005)$ were used as the research instrument. They include six affective and four behavioral items for use in musical contents. The six affective indicators are alert, active, exited, cheerful, satisfied, and involved. The four behavioral indictors are deliberate gesture, expansion, self-assignment, and self-correction. St-Joun, (2004) and Costodero(2005) operationally defined them as follows:

Alert: "density of gaze and facial attention and erect physical position" (St. John, 2004, p258).

Active: "large numbers of verbal and physical responses of the participants to the event" (St. John, 2004, p258).

Exited:"exaggeration in physical response and great interest to share experiences with others" (St. John, 2004, p258).

Cheerful: "high positive interaction with others, such as teachers and peers" (St. John, 2004, p258).

Satisfaction: "an expression of spontaneously heightened positive affect at the conclusion of an event or subset of an event" (St. John, 2004, p258).

Deliberate gesture: "showing very focused and controlled movements often exaggerated but without extraneous motion" (St. John, 2004, p257).

Expansion "making the presented tasks more challenging by transforming them in some ways" (St. John, 2004, p257).

Self-assignment: "initiation of purposeful activities by the participant rather that by the teacher" (Costodero, $2005 \mathrm{p}, 194)$.

Self-correction: "error acknowledgment and adjustment to conform to established rules for an activity in the absence of physical or verbal instruction" (Costodero, 2005 p,194).

\subsubsection{Validity and Reliability of the Research Instrument}

To validate the observational indicators of flow experience introduced by Costodero(1997), some researchers investigated their ability to predict flow among children from 8 months to 8 years of age (Custodero, 1997, 2005; St-Joun, 2004). Researchers found that these indicators were valid tools to predict flow experience in a sample of eleven 4-5 year old children (Custodero, 1997), twenty- nine children within the ages of 25 months to 8 years (Custodero, 2005) and twelve 4-5 year old children (St-Jone, 2004).

In addition, the content validity of the observational indicators of flow experience was confirmed by referring to three specialists in University Putra Malaysia and two other experts. Further, the inter-rater reliability of the research instrument was also proved by doing a pilot study.

\subsection{Data Collection Procedure}

In this repeated measure experimental study with four conditions, data were collected across the experiment through four measurement points. The observational checklist was used to gather data individually during a sixteen minute assessment session at the end of each condition. To collect more precise information, the data collection session for each subject was secretly videotaped, using a video recorder.

To control the experimenter effect during the assessment sessions, which poses a threat to internal validity of the research design, 33\% of the videotaped assessment sessions (Kenedy, 2005) were used to determine the inter-observer reliability. A specialist familiar with the characteristics of the intellectually disabled rated the 40 taped assessment sessions, as a new coder. To clarify the objectives of the study and the operational definitions of the items used in the checklist, a half day training session was conducted by the researcher with the new coder, prior to the rating process. Then, the coder viewed the 40 videotaped assessment sessions and independently coded each session. Inter-rater reliability between the new coder and researcher was calculated based on the Kennedy (2005) approach, where the smaller score of a particular behavior determined by one observer is divided by the larger score of that behavior determined by the other observer and multiplied by 100 . The results of the inter-rater reliability showed that the mean percentage of total agreement between raters was $80.5 \%$ with a range of $76.5 \%$ to $83 \%$. As Kircaali-Iftar \& Tekin (1998 in Yildram Dogru, 2009) mentioned, the acceptable coefficient of inter-rater agreement in behavioral science is $80 \%$ and the coefficient of ideal inter-rater reliability is $90 \%$. Therefore, the ranges of inter-rater agreement in this study could be considered as an acceptable coefficient of inter-rater reliability. 


\subsection{Data Analysis Procedure}

In this study, the data analysis involves three stages: exploratory data analysis, descriptive data analysis, and inferential data analysis. Exploratory data analysis (EDA) was used to examine all the data in detail before undertaking any specific statistical analysis. It was used to identify the outliers, and to assess the normality of score's distribution. In this process, the raw scores were analyzed graphically using box plots and histograms. The box plots were used to find outliers, and histograms with their levels of skewness used to check the normality distribution of scores in each condition of the experiment.

The box plots showed that there were two outliers among the flow experience scores in condition two and no outliers in conditions one, three, and four. After transforming the outliers in condition two by replacing them with the mean plus two standard deviations (Field, 2009), the histograms revealed that the distribution of flow experience scores in condition one was negatively skewed (skewness $=-.46$ ) and the Fisher's coefficient of skewness was -1.09 . The distribution of flow experience scores in condition two was positively skewed (skewness $=.84$ ) and the Fisher's coefficient of skewness was 2. The distribution of flow experience scores in condition three, on the other hand, was negatively skewed (skewness = -.41) and the Fisher's coefficient of skewness was -.97 . Finally the distribution of flow experience scores in condition four resembled a bell shape with a low negative skewness (skewness $=-.16$ ) and the Fisher's coefficient of skewness was -.38 . Since the Fisher's coefficient of skewness of flow experience scores distributions in the four conditions of the experiment were between -2 and +2 , according to Laurentis, Mainoet, and Molteni (2010), the scores distributions in each condition could be considered as normal distribution. Thus, repeated measure ANOVA and its comparison in pair, as parametric test statistic, were used to determine the differences in the level of flow experience between the four conditions of the experiment.

\section{Results}

\subsection{The Results of Descriptive Data Analysis}

The result of descriptive data analysis of flow experience scores are presented in Table 1. As can be seen in this table, the mean scores in condition one was 3.246 and its standard deviation was .43, which indicated a high level of flow experience in this condition, where the participants were provided with optimal challenges for the first time. However, in condition two, where no optimal challenge was provided, the mean scores decreased to a lower level of 1.67 with a standard deviation of .32. In condition three, where optimal challenge were provided for the second time, the mean scores of flow experience increased to a high level of 3.27 with a standard deviation of .46. Finally, the level of flow experience was in a high level with a mean of 3.38 and standard deviation of .35 in condition four, where the participants were stimulated to seek-out optimal challenge.

\subsection{The Results of Repeated Measure ANOVA}

The results of Mauchly's test statistics showed that the assumption of sphericity had been violated, $\mathrm{X}^{2}(5)=$ 23.114, $p<.001$. It means there was no homogeneity of covariance in flow experience scores between the pairs of the conditions. Thus, it was essential to apply a correction to compensate for the violation of sphericity assumption. By looking at the results of Mauchly's test of sphericity, it was seen that the degree of sphericity using Green house-Geisser correction was .726. Since this value was less than .75, according to Leech, Barrett, and Morgan(2007), this correction was selected as the best choice for adjusting $\mathrm{df}$ and reporting the $F$ value in repeated measure ANOVA. Thus, repeated measure ANOVA of flow experience scores, in which the $F$-value was calculated based on both assuming sphericity and Greenhouse-Gessier correction, was conducted. The results of this analysis are presented in Table 2.

With Greenhouse-Gessier correction to overcome sphericity violation, the results(Table 2) indicated that the means of flow experience scores were significantly different with large effect size (Cohen, 1988) across the four conditions of the experiment, $F(2.179,63.191)=187.097, P<.001$, eta ${ }^{2}=.86$. It means the intellectually disabled participants showed statistically significant different levels of flow experience over time across the four conditions of the experiment.

\subsection{The Results of Pair Wise Comparisons}

The results of pair wise comparisons of flow experience scores with Bonferroni correction are presented in Table 3. As can be seen in this Table, the high levels of flow experience in condition one, where optimal challenge was provided for the first time, significantly decreased to a lower level in condition two, where no optimal challenge was provided, $p<008, \mathrm{r}=.95$. The level of this variable again significantly increased to a higher level in condition three, where optimal challenge was provided for the second time, $p<.008, \mathrm{r}=.94$. It still remained at the high level without any significant change in condition four, where the participants were stimulated to look for 
optimal challenge, $p>.008, \mathrm{r}=.43$.

\section{Discussion}

The high levels of flow experience in the first, third, and fourth conditions of the experiment in comparison with its low level in condition two, confirmed the importance of optimal challenge in promoting flow experience, among people with intellectual disability, as expounded by Csikszentmihalyi's (1975) theory of flow experience. Further, in line with Sackett (2008), and Rheinberg \&Vollmeyer (2003), the findings proved the positive effect of optimal challenge in facilitating flow experience, while the other facilitators including immediate feedback and clear goals (Csikszentmihalyi, 1975), were held constant. However, unlike previous studies which confirmed this effectiveness in situations with unreal challenge-skill balance, in which limited levels of challenge were prepared for all participants without taking into consideration their skill levels, this study, in line with Keller and Belles (2008), confirmed this effectiveness in a situation with real challenge-skill balance, in which the challenge level was balanced with the skill level of each participant individually.

On the other hand, the low level of flow experience in the second condition of the experiment, where no optimal challenge was provided, confirmed one motivational problem of people with intellectual disability that is their low tendency to sustain flow experience by looking for new challenges. According to the theory of flow experience (Csikszentmihalyi, 1982), flow is an unstable status which forces people to seek-out optimal challenge as their skills' level improve through practice. As the activity continues, the skill level increases through practice and the person gradually becomes more skillful. To avoid the feeling of boredom and to sustain the flow, a more skillful person seeks a higher challenge level by becoming involved in curiosity or innovative behaviors. However, as the findings of the current study revealed, our intellectually disabled participants did not show such behaviors to sustain flow experience in the boring situation of the experiment. In other words, although the skill levels of the participants improved through practice in the first condition of the experiment, they were unable to sustain flow by looking for new challenges in the second condition. One possible explanation for the low tendency of the intellectually disabled to sustain flow experience by seeking new challenges could be that provided by Zigler and Bennett-Gates (1999). They mentioned that, due to their experience of repeated failures especially in different mastery situations, people with intellectual disability may have a low tendency to participate in new mastery situations or look for new challenges in such situations. The results of the current study relatively supported this assumption and confirmed the low desire of the intellectually disabled to seek-out new challenges by becoming involved in innovative behaviors, when they are in a boring situation with no challenging outcome. Consequently, they demonstrated significantly low level of flow experience in such situations.

Although, our intellectually disabled participants showed a low tendency to sustain flow experience in the second condition of the experiment, they experienced a high level of flow in the third and fourth conditions, where they were provided with optimal challenge or stimulated to look for new challenges. In other words, the intellectually disabled participants were able to maintain flow experience when successful optimally challenging experiences were provided for them or when they were stimulated to be involved in successful innovative behaviors.

Thus, from the findings of the current study, it could be concluded that optimal challenge is an influential facilitator of flow experience among people with intellectual disability. However, due to their low tendency to seek-out new challenges resulting from their negative life experiences, these people may be unable to sustain flow experience by looking for new optimal challenge. However, providing successful experiences with optimal challenge for these people or stimulating them to look for new challenges, using special strategies could facilitate their flow experience.

\section{Practical Implications}

The findings of the current study have some important practical implications for those who plan to facilitate flow experience among people with intellectual disability, using special programs such as a music intervention program. As the results of the current study showed, providing successful experiences with optimal challenge in a music intervention program is an influential factor in promoting flow experience. However, in order to provide such experiences, there are some prerequisite criteria to be met. The first criterion is providing a set of tasks, from very simple to more complex ones, with unlimited challenge levels. By using such tasks, appropriate levels of challenge are provided for the participants as their skill levels improve through practice. It is revealed that activities such as sealing envelops, packing, sorting, and folding pamphlets, found in some vocational training centers and sheltered workshop for the intellectually disabled people in Malaysia do not provide appropriate challenge for the participants to experience flow. In contrast, some musical or other activities, which include a 
set of tasks with unlimited challenge levels, could provide enough challenge for the participants as their skill levels develop through practice.

The second criterion is preparing a situation with a real challenge-skill balance. A situation with real challenge-skill balance is where the challenge level is balanced for each participant individually based on his/her skill's level. This criterion is particularly necessary for the intellectually disabled people who have a variety of individual differences. A situation where the same level of challenge is provided for all participants with different skill levels as in group activities cannot provide a real challenge-skill balance. Consequently it might not be able to facilitate flow experience especially among the intellectually disabled participants. Thus, in order to provide optimal challenge for the intellectually disabled people, it is essential to provide a real challenge-skill based on the skill level of each participant in an individualized intervention program.

As the findings of the current study revealed, an alternative strategy to facilitate flow experience among people with intellectual disability could be stimulating them to seek-out optimal challenge by being involved in successful innovative behaviors. However, to foster such behaviors, it is necessary to use some scaffolding strategies, zone of proximal development, and modeling creative features.

\section{Conclusion}

The strategies presented in this paper are an attempt to combine theoretical perspectives and empirical findings with pedagogical practices, to facilitate flow experience in people with intellectual disability, using a music intervention program. In doing so, it is hoped that the intellectually disabled are able to experience flow when performing musical tasks, if they are provided informative feedback, and clear goals. Further, due to their low tendency to look for new challenges, providing successful musical experiences with optimal challenge or stimulating them to seek innovative challenges, could facilitate flow experience in these people. However, further research is needed to determine the extent to which the strategies presented here have an impact on promoting flow experience, when other intervention programs are used.

\section{Acknowledgement}

The authors would like to thank Mr Kamaraj, the manager of Selangor and Federal Territory Association for the Mentally Handicapped for the support and facilitation during the experiment and data collection.

\section{References}

Bitcon, C. H. (2000). Alike and different: the clinical and educational uses of Orff-Schulwerk (2 ed.): Barcelon Publisher, Gilsum NH.

Cohen, J. (1988). Statistical power analysis for the behavioural sciences (2 ed.). New York: Academic Press.

Csikszentmihalyi, M. (1975). Beyond boredom and anxiety: The experience of flow in work and games. Sanfrancisco: Jossey-Bass.

Csikszentmihalyi, M. (1982). Towards a psychology of optimal experience. In Review of personality and social psychology (Vol. 2): Beverly Hills, CA: sage

Csikszentmihalyi, M. (1990). Flow: The psychology of optimal experience. New York: Harper and Row.

Csikszentmihalyi, M. (1996) Finding Flow: The psychology of engagement with everyday life. New York: Basic Books.

Csikszentmihalyi, M. (2003): "Materialism and the Evolution of Consciousness." In: T. Kasser, A.D. Kanner (eds.),Psychology and Consumer Culture. the Struggle for a Good Life in a Materialistic World. Washington: APA.

Custodero, L. A. (1997). An observational study of flow experience in young children's music learning. Southern California.

Custodero, L. A. (2005). Observable indicators of flow experience: A developmental perspective on musical engagement in young children from infancy to school age. Music Education Research, 7(2), 189-209. http://dx.doi.org/10.1080/14613800500169431

Deci, E. L., \& Ryan, R. M. (1985). Intrinsic motivation and self-determination in human behavior. New York: Plenum Press.

Field, A. (2009). Discovering statistics using SPSS (3 ed.): SAGE Publication Ltd.

Foreman, P. (2009). Education of students with intellectual disability: research and practice. United States: Information Age Publishing Inc. 
Fredderic, G., Vallerand, R. J., \& Blanchard, C. (2000). On the assessment of situational intrinsic and extrinsic motivation: the situational motivation scale(SIMS). Motivation and Emotion, 24(3), 175-213. http://dx.doi.org/10.1023/A:1005614228250

Gravetter, F. J., \& Forsano, L. A. B. (2008). Research method for the behavioral sciences (3 ed.). USA: Wadsworth Cengage Learning.

Harter, S. (1978). Effectance motivation reconsidered: toward a developmental model. Human Development, 21(34), 34-64. http://dx.doi.org/10.1159/000271574

Keller, J., \& Bless, H. (2008). Flow and regulatory compatibility: an experimental approach to the flow model of intrinsic motivation. Personality and Social Psychology Bulletin, 34, 196-209. http://dx.doi.org/10.1177/0146167207310026

Kenedy, C. H. (2005). Single-case designs for educational research: Pearson Education Inc, Allyn and Bacon Laurentis, G. D., Maino, R., \& Molteni, L. (2010). Developing, validating and using internal rating: methodologies and case studies: John Willy \& Sons Ltd.

Leech, N. L., Barrett, K. C., \& Morgan, G. A. (2007). SPSS for intermediate statistics : use and interpretation (3 ed.). New York: Lawrence Erlbaum Associates.

Rheinberg, F., \& Vollmeyer, R. (2003). Flow experience in a computer game under experimentally varied conditions. Zeitscherift Fur Psychologie, 211, 161-170

Sackett, A. L. (2008). Promoting flow: an investigation of the effect of various task condition on flow. State University of New York.

St- Joun, A. (2004). An investigation of the relationship between flow experience and the role of scaffolding in Kindermusik classroom. Columbia university.

Taylor, Richards, S. B., \& Brady, M. P. (2005). Mental retardation: historical perspective, current practice and future directions. Boston: Pearson Allyn and Bacon

West, S. G., Biesanz, J. C., \& Kowok, O.-M. (2004). Within-subject and longitudinal experiments design and analysis issues. In The Sage handbook of methods in social psychology: Sage Publication,Inc.

Yildram Dogru, S. S. (2009). Teaching of tactile perception skills to children with autism in early childhood. Ozean Journal of Social Sience, 2(3), 157-166

Zigler, E., \& Bennett-Gates, D. (1999). Personality development in individuals with mental retardation: The Press Syndicate of the University of Cambridge.

Table 1. The results of descriptive data analysis of flow experience scores

\begin{tabular}{|l|l|l|l|l|}
\hline Variable & Minimum & Maximum & Mean & S.D. \\
\hline Flow Experience 1 & 2.11 & 3.88 & 3.246 & .43 \\
\hline Flow Experience 2 & 1.22 & 2.55 & 1.67 & .32 \\
\hline Flow Experience 3 & 2.44 & 4.00 & 3.27 & .46 \\
\hline Flow Experience 4 & 2.77 & 4.00 & 3.38 & .35 \\
\hline
\end{tabular}

Table 2. The results of repeated measure ANOVA of flow experience scores

\begin{tabular}{|l|l|l|l|l|l|l|}
\hline \multirow{2}{*}{ Source } & Df & Mean Square & F & Sig & $\begin{array}{l}\text { Partial Eta } \\
\text { Squared }\end{array}$ \\
\hline \multirow{2}{*}{ Condition } & Sphericity Assumed & 3 & 19.866 & 187.097 & .000 & .86 \\
\cline { 2 - 8 } & Greenhouse-Gessier & 2.179 & 27.352 & 187.097 & .000 & .86 \\
\hline \multirow{2}{*}{ Error } & Sphericity Assumed & 87 & .106 & & & \\
\cline { 2 - 7 } & Greenhouse-Gessier & 63.191 & .146 & & & \\
\hline
\end{tabular}


Table 3. The results of pair wise comparisons of flow experience scores

\begin{tabular}{|l|l|l|l|l|}
\hline $\begin{array}{c}\text { Condition 1 } \\
\text { Vs } \\
\text { Condition 2 }\end{array}$ & Means Differences & Std. Error & Sig & R \\
\hline $\begin{array}{c}\text { Condition 2 } \\
\text { Vs } \\
\text { Condition 3 }\end{array}$ & -1.567 & .091 & .000 & .95 \\
\hline $\begin{array}{c}\text { Condition 3 } \\
\text { Vs } \\
\text { Condition 4 }\end{array}$ & -.115 & .045 & .000 & .94 \\
\hline
\end{tabular}

